\title{
Mass Transit Policy: Responding to COVID-19
}

\author{
Susan E. Baer, PhD \\ Walden University, Minneapolis, Minnesota, United States \\ iD https://orcid.org/o00o-0003-2302-4390 \\ George R. Larkin, PhD \\ Walden University, Minneapolis, Minnesota, United States \\ (iD https://orcid.org/oooo-0001-5794-5863
}

Contact: susan.baer@mail.waldenu.edu

\begin{abstract}
Mass transit is vital to daily life in U.S. cities and many other cities throughout the world. Mass transit systems are vulnerable to pandemics like COVID-19 and other less serious threats. Post COVID-19 mass transit policy must be different than its predecessors if mass transit is to provide a reliable, sustainable, and equitable means of transportation. Future mass transit systems will be the outcome of public health, technological, economic, and political considerations. This paper provides an initial attempt to identify and discuss these four considerations as most relevant to the development of an equitable and efficient mass transit policy for rail and bus systems.
\end{abstract}

Keywords: mass transit; mass transit policy; public transit; COVID-19; rail; subway; bus

Date Submitted: December 18, 2020 | Date Published: May 5, 2021

\section{Recommended Citation}

Baer, S. E., \& Larkin, G. R. (2021). Mass transit policy: Responding to COVID-19. Journal of Social Change, 13(2), 11-23. https://doi.org/10.5590/JOSC.2021.13.2.02

\section{Introduction}

In the early morning of May 6, 2020, the New York City Subway System was deliberately closed for the first time in 115 years (Goldbaum, 2020b). Authorities closed the system for cleaning and disinfecting to help stop the spread of COVID-19. Mass transit proves vital to daily life in New York City and many other places throughout the world, but mass transit systems are vulnerable to pandemics and other less serious threats. Post COVID-19 transit system policy must be different than its predecessors if mass transit is to provide a reliable, sustainable, and equitable means of transportation for large numbers of people. Transportation policymakers must consider a multitude of factors when formulating solutions to our mass transit needs, including public health, technological, economic, and political considerations. This paper's goal is to provide an initial attempt to identify and discuss these four considerations as being most relevant to the development of a public transit policy for rail and bus systems. The paper begins with a brief overview of present conditions for context. 


\section{Current Conditions}

The American Society of Civil Engineers (ASCE), in their latest Infrastructure Report Card, gave public transit in the United States a grade of D- on a scale from A to F, based on criteria including capacity, condition, funding, future need, operation and maintenance, public safety, resilience, and innovation. The ASCE report, issued before the COVID-19 pandemic, noted that the use of public transit was growing while the system simultaneously suffered from funding shortfalls for maintenance and investment. Many public transit vehicles, maintenances facilities, guideways, power and communication systems, and stations are in disrepair. In 2015, the federal government estimated it would take $\$ 90$ billion to bring the country's public transit systems up to standards. The deficits in public transit maintenance and investments were estimated to grow to $\$ 122$ billion by 2032 (ASCE, 2017).

Even with its shortcomings, public transportation in the United States continues to be an important means of mobility for many people. Each year, the American Public Transportation Association (APTA) produces a factbook that provides a snapshot of the industry. APTA (2020b) released the most recent edition of the factbook in March 2020 at about the same time the COVID-19 pandemic lockdowns occurred throughout the United States. The following summary highlights some of the more salient information in the publication.

- There are 2,207 public transportation systems operating in the United States with 1,279 systems operating in rural areas and 928 in urban areas.

- Public transportation systems operate 181,541 railcars, buses, vans, and other types of vehicles.

- From 1998 to 2018 public rail operations increased by $57 \%$ from 54 to 93 systems.

- From 1998 to 2018 the number of total passenger miles on public transit increased from 44.1 to 55.8 billion.

- Pre-COVID-19 growth in ridership on public transportation has exceeded overall population growth in the United States.

- Most public transportation trips are divided evenly between buses and rail.

- $\quad$ Fifty percent of all public transportation trips are made by individuals going to and from work.

\section{Public Health and Technological Considerations}

Policymakers usually discuss mass transit as a form of hard or physical infrastructure, but it also serves as a form of social infrastructure (Klinenberg, 2018). Social infrastructure is defined as "the physical places and organizations that shape the way people interact" (Klinenberg, 2018, p. 5). Not to be confused with social capital, social infrastructure consists of the physical conditions that determine whether social capital develops. While a system designed for private vehicles will likely keep people separate, a system designed for mass transit that uses buses and trains can enhance civic life and, thus, counts as social infrastructure. A city without mass transit would involve a random mass of people traveling in a random way (Iclodean et al., 2020).

Mass or public transit systems do not necessarily lead to social isolation. A 2013 study of railway systems found that people form transient communities as they ride through cities (De Sapio, 2013). The daily experience of spending time on a crowded train rarely leads to long-term relationships, but it helps people deal with density, diversity, difference, and other people's needs. It also exposes people to unexpected behavior and challenges stereotypes about group identity. Indeed, the subway serves as New York City's main 
social artery and its largest and most heterogeneous public space, promoting interaction across group lines (Klinenberg, 2018).

The COVID-19 public health crisis has severely strained the world's mass transit systems and their policies, and transit systems have responded and adapted quickly to the changed public health terrain in order to attempt to keep transit employees and passengers safe. When states first began to implement stay-at-home orders in March 2020 as a result of the COVID-19 pandemic, public transit systems encouraged people not to ride unless the trip was essential. Public transit ridership across the United States plummeted as a result, decreasing an average of 90\% for rail and 70\% for bus ridership (Skoutelas, 2020).

Evolving policies that respond to COVID-19 affect public transit systems as both hard infrastructure and social infrastructure, and these policies often involve the use of new technology. As examples, the Chicago Transit Authority started an online information dashboard to let passengers know when buses are crowded, and Boston introduced a real-time congestion tracker for bus lines in order to help riders make informed decisions about travel times (Cusumano, 2020). The Dallas Area Rapid Transit installed respiratory droplet shields on buses in order to protect passengers and employees. The Beaver County Transit Authority in Pennsylvania began a new hands-free ticketing policy (Skoutelas, 2020). Orlando, Florida, and Philadelphia, Pennsylvania, began using heavy disinfectant protocols, recommended social distancing, and encouraged or required passengers to wear face masks (Durkin \& Kapos, 2020).

Although transit systems have implemented new policies, public transit employees and passengers are still at risk of contracting COVID-19. Fourteen percent of transit workers in New Orleans have tested positive for the virus (Verma, 2020). An August 2020 survey found that almost 25\% of New York City transit workers had contracted the virus (Berger, 2020b). The Metropolitan Transportation Authority (MTA) requires both New York City transit workers and passengers to wear face masks, and it has distributed over a million masks to passengers. According to MTA Chairman Patrick Foye, 90\% of New York City subway riders comply with mask requirements. New York Governor Andrew Cuomo announced in September 2020 that New York City subway and bus riders would be fined $\$ 50$ if they refuse to wear a face mask (Vielkind \& Berger, 2020).

The National Academies of Sciences, Engineering, and Medicine (2014) recommend that transportation agencies have a pandemic plan. The MTA, run by the state of New York, is responsible for New York City's subway system, which has more stations than any other city in the world ("The destiny of density," 2020). As a result of the COVID-19 pandemic, the MTA introduced a 13-point action plan for a safe return to its subways and buses. The elements of the plan include increasing service, cleaning and disinfecting, testing innovative cleaning solutions, mandating face coverings, keeping employees safe, enhancing safety and security, deploying hand sanitizer, installing floor markings and arrows, staggering business hours, distributing masks, continuing contactless payments, gaining new partnerships and technology to make the system safer, and launching a data dashboard (MTA, n.d.).

Multiple examples demonstrate how the MTA is implementing its 13-point action plan by using technology during the pandemic. It is trying ultraviolet light to kill the coronavirus, and employees get temperature checks when they arrive at work. The MTA is considering additional options such as taking reservations for subway seats or metering to limit the number of people on a bus or in a rail station (Durkin \& Kapos, 2020). The MTA is also introducing sensors to count the number of passengers on buses, and it then conveys this information to potential passengers through the agency's app (Cusumano, 2020). In addition, fresh air replaces filtered air circulating through a New York City subway car at least 18 times an hour which is thought to reduce the threat of a COVID-19 super-spreader event on subway trains as long as trains do not become too crowded and people continue to wear face masks (Goldbaum, 2020a).

Ridership could bounce back faster in buses than rail systems due to buses having even better ventilation. MTA is trying to develop a plan to operate many more buses with many fewer passengers. This will require 
enhanced signal timing, improved access around bus stops, and strict enforcement of bus lanes. Bill de Blasio, the mayor of New York City, has so far provided 30 kilometers of new bus lanes ("The destiny of density," 2020). In addition, the city needs better sidewalks and bike lanes. Mayor de Blasio has been pressured to pedestrianize streets so people can keep a safe distance from each other as well as increase plans for the use of bicycles in the city ("The destiny of density," 2020).

While it is a global public health crisis, many urbanists believe the COVID-19 pandemic also provides the opportunity for New York and other cities to reduce their dependence on cars. More than half of New York City's households do not own cars. Of those who do own cars, most do not use them for commuting. Of the 1.6 million commuters who came into Manhattan every weekday before COVID-19, more than 80\% made the trip via subway or public bus or by walking or biking. Only about $12 \%$ of daily commuters reached Manhattan by private car before the pandemic (Manjoo, 2020).

The firm Practice for Architecture and Urbanism (PAU) is working on a proposal that would ban privately owned cars in Manhattan (Manjoo, 2020). PAU argues that cars waste land and take up too much physical space to transport too few people. In Los Angeles, for example, land for parking is greater than the entire land area of Manhattan, enough space to house almost a million more people at Los Angeles' current density (Manjoo, 2020). Without private cars, Manhattan's streets could include bike superhighways and bus rapid transit. Such a bus system would have dedicated lanes in the road, creating a system that approaches the capacity, speed, and efficiency of the subway at a fraction of the cost (Manjoo, 2020).

The Monterey-Salinas Transit District (MST) serves one-fifth of the California coast from Paso Robles to San Jose and has a service area of almost 300 square miles (Smith, 2020). MST developed a business continuity plan 5 years ago that included a section on pandemic response, but it did not anticipate the extended length of the COVID-19 pandemic. It has taken numerous steps to respond to COVID-19, including giving its drivers masks, goggles, and face shields and installing plastic shields in the front of buses to provide additional protection to drivers. It restricted bus occupancy to ensure social distancing of passengers, who are also required to wear face masks, and it installed video cameras on buses to monitor driver and passenger compliance with public health guidelines (Smith, 2020). MST also found new ways to serve the community during the COVID-19 pandemic. In one example, it parked its Wi-Fi-enabled buses in rural areas to provide hot spots for students who were having difficulty keeping up with remote learning requirements. MST also donated two of its buses for use as COVID-19 testing facilities for agricultural workers (Smith, 2020).

Unlike traditional public transit, the private bus industry, which also transports commuters in major cities such as Washington, DC, and New York, has received no governmental economic relief as a result of COVID19. This industry has so far been left to survive on its own while Congress gave $\$ 25$ billion in grants and loans to public transit agencies in the $\$ 2$ trillion coronavirus relief package approved in late March 2020 (Lazo, 2020). The private bus industry hopes to receive aid in a second governmental relief package. Approximately 3,000 private bus companies in the United States carry 600 million passengers each year. In comparison, airlines carry 700 million domestic passengers in the United States annually (Lazo, 2020).

Other countries have also changed their public transit policies to respond to COVID-19. In addition to a requirement that passengers wear face masks, officials use an infrared thermometer to measure passengers' body temperatures at the Wuchang Railway Station in Wuhan, China ("Journey to recovery," 2020). Cities such as Paris, France, are adding hundreds of miles of bike and pedestrian paths (Berger, 2020a). Government officials have also enacted strict social distancing measures in the Paris region's public transit systems, mandating that there can be no more than one passenger per square meter on trains (Morenne \& Ngo, 2020). The city's commuters may also receive a $\$ 151$ fine if they do not wear a face mask. As a result of social distancing measures, trains that normally carry 2,600 passengers only carry 700. The city has painted white dashes, lines, and arrows on Paris rail station floors to control passenger movement. Transit employees disinfect trains thoroughly every day, and employees clean station seats, vending machines, and handrails 
throughout the day. Thirty-five contractors distribute hand sanitizer to passengers in the city's seven busiest train stations (Morenne \& Ngo, 2020).

Technological advancements have also made it possible to implement autonomous vehicles (AVs) for public transit, and AVs may prove advantageous during a pandemic. The shuttle bus transport capacities currently in use in AVs are low, with a maximum of 15 passengers, but various urban areas currently utilize them (Iclodean et al., 2020). Benefits of autonomous driving include replacement of the human driver who has emotional and physical limitations, as well as the possibility of the AV making predictions and communicating with infrastructure and other vehicles. In the United States, regulations about the safety of AVs are subject to state governments, and their registration and application to public roads are subject to the laws of the national government (Iclodean et al., 2020).

The advantages of autonomous shuttle buses include traffic jam reductions, increased operating times, road safety, pollution reduction, schedule reliability, automatic and interactive fleet management, new working places, and new uses or purposes for autonomous public transit during a pandemic. For example, AVs can transport patients between hospitals while avoiding human interaction and can also transport medical samples or tests. Disadvantages of autonomous shuttle buses include driver vacancy, increased cost of maintaining and upgrading a fleet, security risks, and lack of response in the event of a malfunction. AV technology requires years of testing before it can replace large-scale public transit using traditional buses. Autonomous shuttle buses currently serve niche areas of public transit, such as night routes with reduced traffic and routes through airports, industrial parks, and commercial areas (Iclodean et al., 2020).

\section{Economic Considerations}

The COVID-19 pandemic may have adverse economic impacts on three groups of public transportation stakeholders. First, as previously noted, the agencies that operate public transportation systems often lacked sufficient funds to cover operating and capital expenses before the pandemic. COVID-19 will make a bad situation worse. Transit workers are a second group that may suffer adverse economic impacts from the pandemic. Finally, regular users of public transportation, many of whom are already at risk economically, may experience additional economic hardships. An attempt to provide a detailed and accurate accounting of COVID-19's economic impacts on stakeholders is premature. However, some preliminary damage assessments can provide useful information for those charged with designing public transportation policies to lead us through and beyond the pandemic.

\section{Operators}

Overall, public transportation agencies self-generate $29.5 \%$ of the monies needed to operate, maintain, and upgrade their systems. The federal government provides the agencies with $15.8 \%$ of their funding and the remainder, 54.6\%, of the funds come from state and local governments (EBP US, Inc., 2020). Figure 1 provides a more detailed listing of the sources of revenue for public sector transportation agencies. The economic shutdown associated with the early onset of the COVID-19 pandemic in the United States negatively impacted all sources of funding for public transportation agencies. The CARES Act provided transit agencies with an additional $\$ 25$ billion of funding from the federal government to help offset losses from state and local sources (EBP US, Inc., 2020). 
Figure 1: Sources of Revenue for Public Transportation Agencies

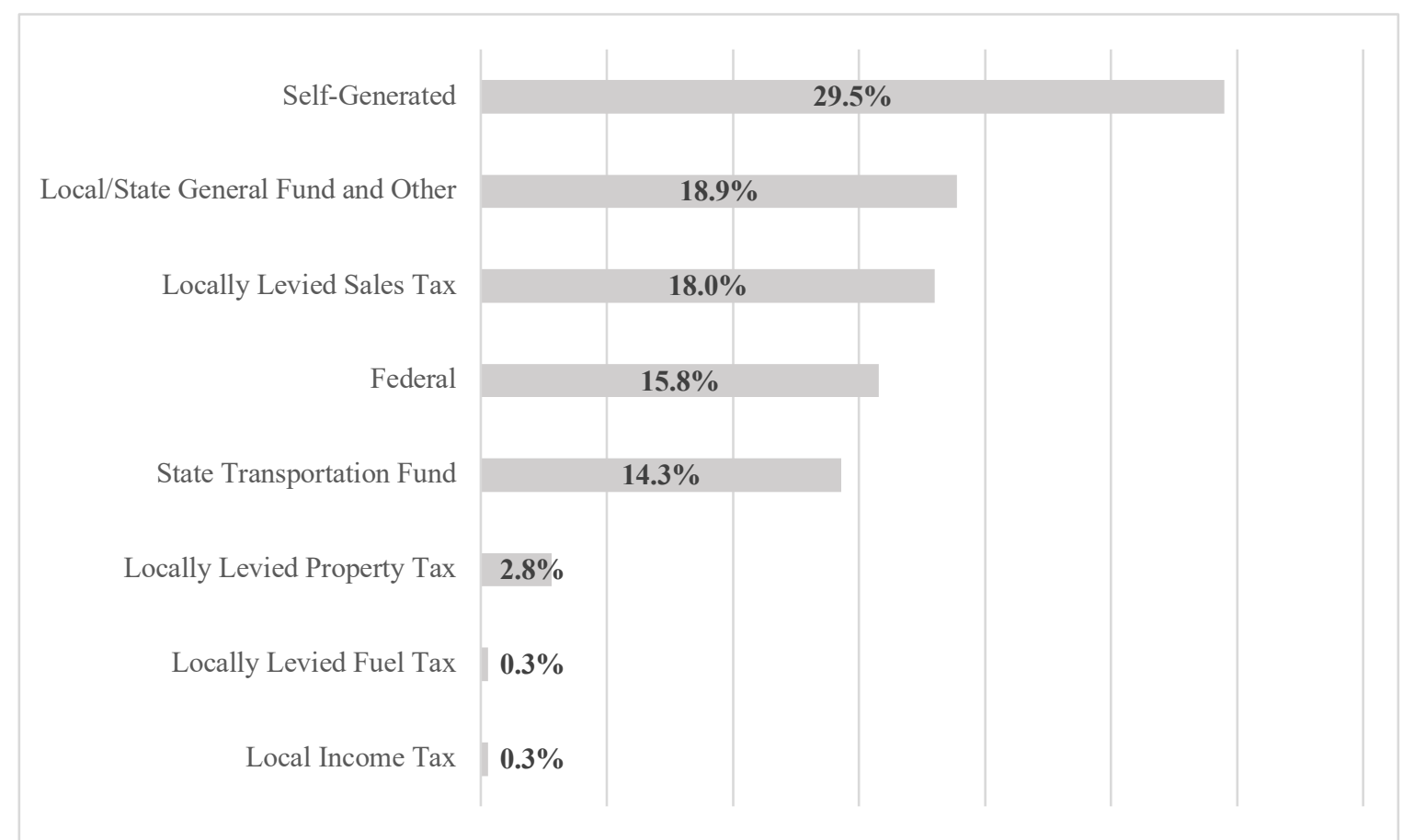

Source: EBP US, Inc., 2020

In May 2020, the consulting firm EBP US, Inc. completed The Impact of the COVID-19 Pandemic on Public Transit Funding Needs in the U.S. for the APTA. The findings of the report presented a bleak picture of the impact of COVID-19 on public transit. The COVID-19 shutdown resulted in a $73 \%$ reduction in public transit ridership and an $86 \%$ reduction in fare or self-generated revenue. Revenue sources used by state and local governments to fund public transportation also decreased dramatically during the initial COVID-19 shutdowns. Transit agencies faced a $\$ 48.8$ billion funding shortfall between the second quarter of 2020 and the end of 2021. Figure 2 shows the estimated peak decline of each source of revenue for public transportation agencies. CARES Act funding reduced the shortfall to $\$ 23.8$ billion through the end of 2021. Projected delays and cancellations due to pandemic-related decreases in capital spending on public transit could lead to the loss of 37,000 construction jobs in 2020 and 34,000 jobs in 2021 (EBP US, Inc., 2020). 
Figure 2: Pandemic Related Declines and Increases in Public Transportation Funding Sources

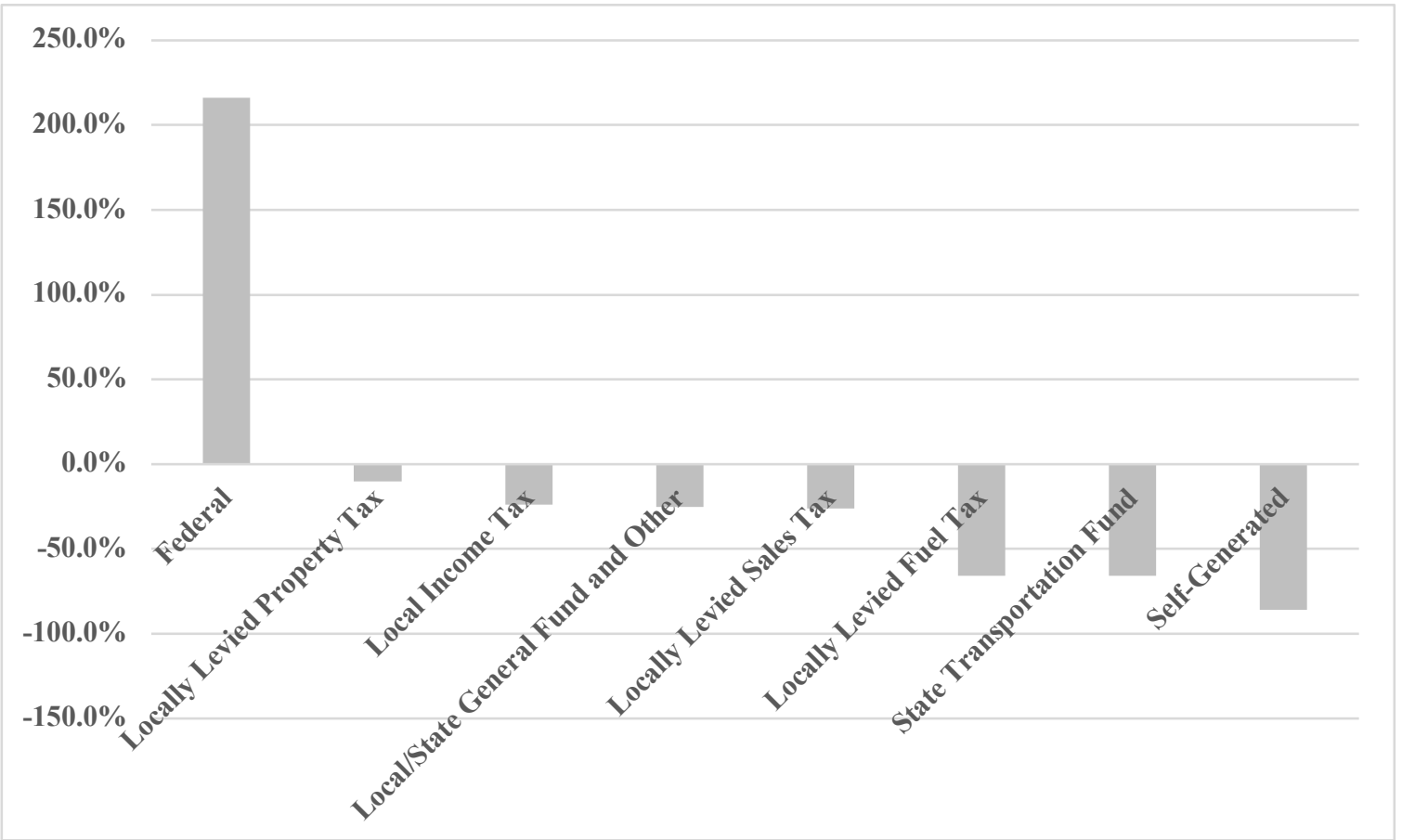

Source: EBP US, Inc. 2020

\section{Workers}

The National Transportation Database (NTD) contains information on 2,208 public transportation agencies that receive federal aid from the Urbanized Area Formula (5307) or Rural Formula (5311) programs. The most recent data reported in the 2020 NTD is from 2018. The agencies reporting to the NTD employed 270,672 workers. The workforce was divided between 253,892 full-time and 16,780 part-time employees. Employees were classified as operations or capital workers. Operations workers were further divided among vehicle operations, vehicle maintenance, facility maintenance, and general administration. The largest number of workers were employed as vehicle operators. Operations workers averaged $\$ 31.99$ per hour. Figures 3 and 4 provide more detailed information about public transportation workers and wages. 
Figure 3: Number of Operations Workers by Categories

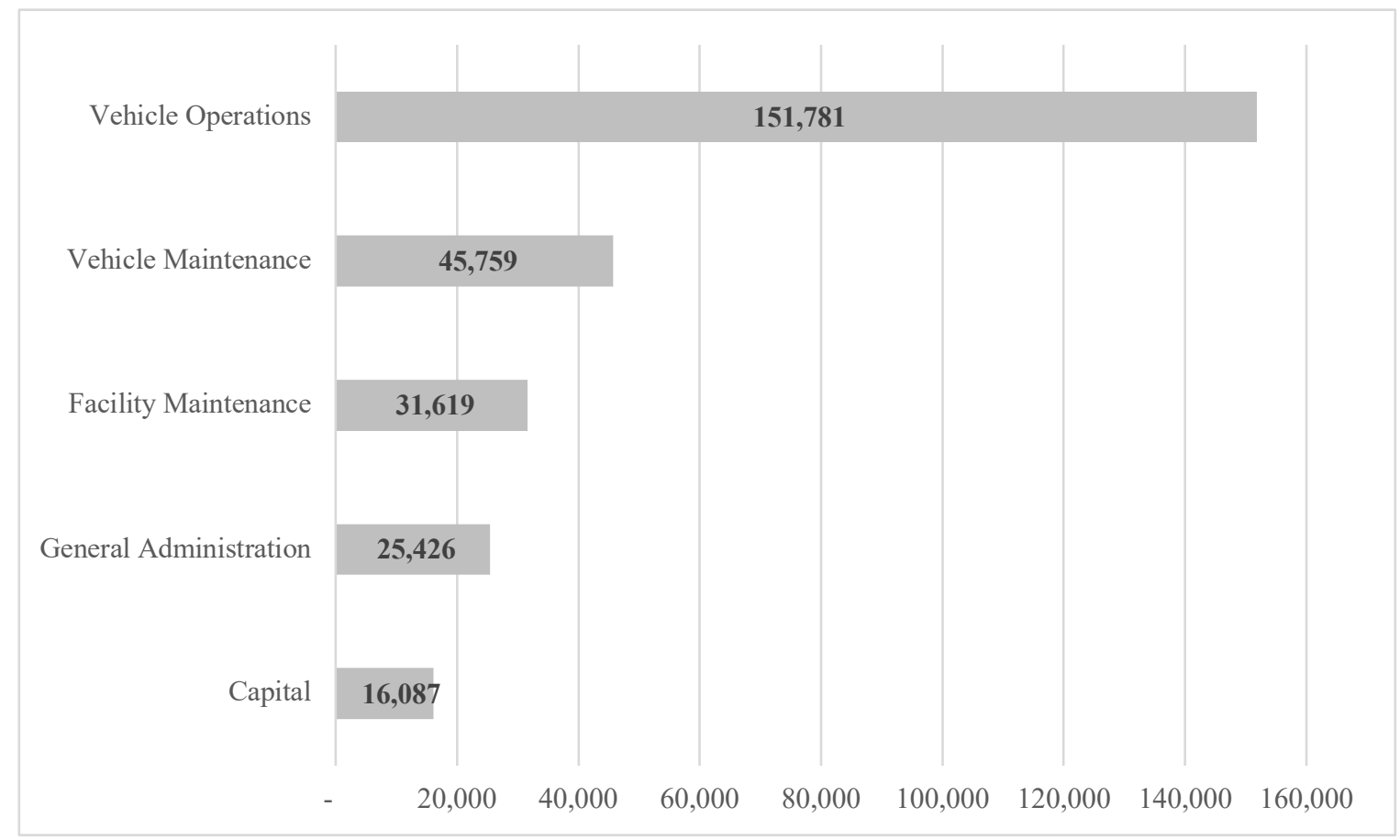

Source: 2018 National Transit Database

Figure 4: Salaries for Operations Workers by Job Classification Categories

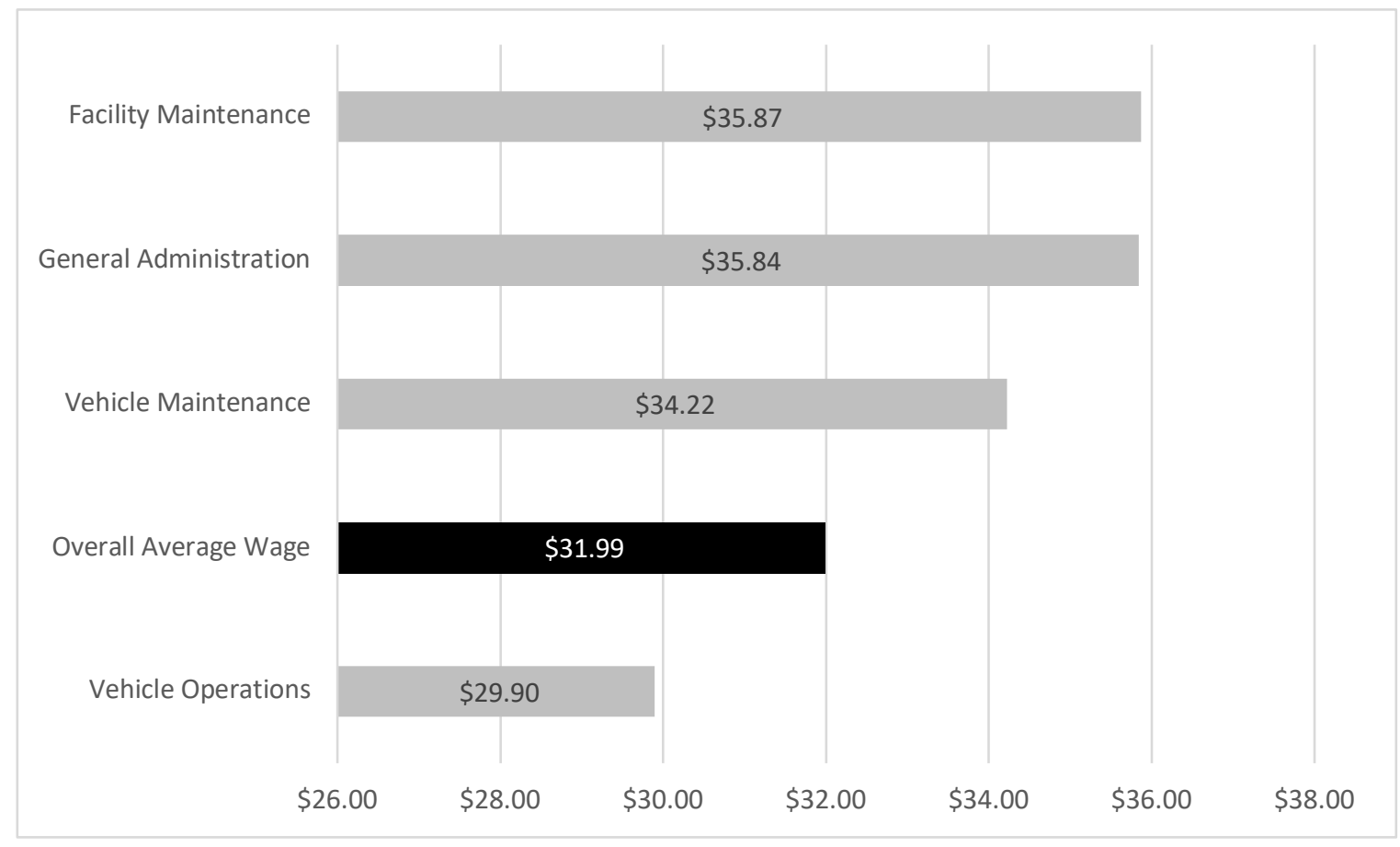

Source: 2018 National Transit Database 
APTA, during the spring and summer of 2020, conducted a series of surveys with public transportation agencies to assess the impact of COVID-19 on their operations. The response rate was not high. However, agencies that responded represented systems that serve a larger portion of all public transit users. The surveys revealed that one-third of all respondents have or plan to furlough workers, and 16\% of respondents have transferred capital funds to operations in order to maintain their workforces (APTA, 2020a). Eighty-three percent of respondents reported they are using their share of the $\$ 25$ billion funding from the CARES Act to maintain their workforces, and the CARES Act funds are being exhausted quickly. The Federal Transit Administration reported that $80 \%$ or $\$ 20$ billion dollars of the CARES Act funds for public transportation were obligated by July 23, 2020 (APTA, 2020).

\section{Users}

COVID-19's adverse impacts on public transportation are not distributed equally throughout our society. Most public transit users, $55 \%$, are women, and $60 \%$ percent are from communities of color. Blacks comprise $13 \%$ of the U.S. population but represent $24 \%$ of public transportation users. Individuals making less than $\$ 15,000$ per year represent $13 \%$ of the population but $21 \%$ of all public transit users (APTA, 2020a).

The most recent census estimated that $10 \%$ of all workers in major cities commute to work on public transit. Minority workers are disproportionately dependent on public transit, with one in six Black and Asian workers using it to commute to work. Minority workers also have lower rates of private automobile ownership and tend to work at occupations that require them to be at the job site rather than having the option of working from home (Tan et al., 2020). For many low-income individuals and people of color, public transportation is essential to their economic survival. As a result of these factors, serious issues of transportation inequity exist.

\section{Looking ahead}

The Transportation Research Board of the National Academies of Sciences, Engineering, and Medicine (TRB) identified 39 current and potential sources of revenue for public transportation. The funding mechanisms comprised five major categories that include traditional tax- and fee-based sources, revenue streams from projects, new user- or market-based funding, financing mechanisms, and community business, activity, and related funding sources. One may use contextual and more generic criteria to evaluate the revenue sources. The first set of criteria accounts for contextual issues particular to individual locales. The contextual criteria include the types of transit agencies and services to be funded, the elements for which funding is being sought, the type of source that is desired and that is appropriate, and local and regional perspectives on the role of public transportation in the community. More generic criteria to determine the advantages and disadvantages of alternative revenue sources include revenue yield, cost efficiency, equity, economic efficiency, political and popular acceptability, and technical feasibility (National Academies, 2009).

\section{Political Considerations}

The post-pandemic politics of public transportation will conform to Lasswell's (1936) observation that politics is the competition that determines who gets what, when, and how. Public transportation will compete for funding with other forms of transportation and other national priorities. The political battles will be fought at all levels of government and will involve race, socioeconomic class, and region of residence.

\section{Race}

As previously noted, the percentage of minority individuals using public transportation is far greater than their overall percentages in the population. Also, people of color have lower rates of individual automobile ownership than other groups (Tan et al., 2020). Therefore, many people of color depend on public transportation to travel to and from work and to perform many of life's everyday tasks. However, in order to secure subsidies necessary to survive, public transit systems have historically appealed to more affluent white voters by focusing on rail systems, which have a better image than buses (Taylor \& Morris, 2015). 
This strategy often proved successful at the polls, but voters have shown less inclination to ride the rail systems they voted to fund. This situation has led to mass transit priorities being designed to appeal to people who rarely or never use the service (Taylor \& Morris, 2015; Karner \& Marcantonio, 2018). This inequitable outcome is even more problematic for mass transit systems currently, given the COVID-19 pandemic. Although serious transportation inequity issues surrounding race exist in the United States, communities of color have begun to form broader coalitions that include environmental organizations, among others, that have enabled them to achieve public transportation equity wins (Karner \& Duckworth, 2019).

\section{Class}

Race and socioeconomic class intersect in the United States (Desmond, 2016). Many people of color who depend on public transportation are also economically distressed (Karner \& Duckworth, 2019). APTA (2020) estimates that 1 in 10 workers in major cities commute to work on public transportation and that individuals making less than $\$ 15,000$ per year represent a disproportionately high percentage of public transportation riders.

While low-income individuals and people of color comprise the majority of public transit riders in the United States, significant differences in income and race or ethnicity also exist by mode of transit. Specifically, poor and minority passengers travel disproportionately on buses versus more affluent whites who tend to travel on rail (Taylor \& Morris, 2015). In addition, bus riders are rapidly growing poorer over time. Rail riders as a group have higher incomes than bus riders. Thus, mass transit ridership in the United States is itself two-tier, another expression of transportation inequity (Taylor \& Morris, 2015).

\section{Region of residence}

The 2018 National Transportation Database (NTD), the most recent release of the product, contains information about 3,698 public transportation agencies. The NTD also offers a window into the regional components of post-pandemic public transportation politics. The agencies covered by the database provided over 53.5 billion passenger miles of transportation services to their users. The 11 largest public transportation agencies provided over one-half of the passenger miles. Four of the agencies are in the State of New York. California, Illinois, and New Jersey each have two agencies, and Washington, DC, has one agency. The four states and DC account for over one-fourth of the population of the United States. However, they have only 8\% of the votes in the United States Senate, which must approve any major federal funding for public transportation (NTD, 2018).

\section{Looking ahead}

The post-pandemic politics of public transportation will be about money and equity. The recent national awakening on racial and social equity could bode well for public transportation funding. However, a multitude of demands influences budgetary politics. One reasonably can assume that federal deficits created by the CARES Act, anticipated diminished revenues, and the economic damage caused by the pandemic will also influence future budgetary debates about public transportation funding.

\section{Conclusion}

Public transportation has received increased attention since the onset of the COVID-19 pandemic. This paper's goal was to identify and discuss public health, technological, economic, and political considerations as being most relevant to the development of a public transit policy for rail and bus systems that responds to COVID-19 and beyond. The paper described multiple new policies that combine public health and technological innovations, which public transit agencies have implemented to respond to the pandemic. In addition, the paper described the pandemic's adverse economic impact on public transportation agencies, including sharp reductions in ridership, which negatively affect agencies' self-generating revenues. As discussed in the paper, the 2020 CARES Act provided $\$ 25$ billion in economic relief to public transportation 
agencies, with the majority of funds obligated by July 2020. The paper also highlighted the political issue of public transportation inequity. Low-income individuals and people of color are disproportionately dependent upon public transit, and this inequity has become even more concerning during the pandemic. The four considerations discussed in this paper may prove useful to policymakers charged with shaping an equitable and efficient public transportation system. 


\section{References}

American Public Transportation Association. (2020a, April 27). Who rides public transportation. https://www.apta.com/research-technical-resources/research-reports/who-rides-publictransportation/

American Public Transportation Association (2020b, May 18). Public transportation fact book. https://www.apta.com/research-technical-resources/transit-statistics/public-transportationfact-book/

American Society of Civil Engineers. (2016, October 27). America's infrastructure grade. ASCE’s 2017 Infrastructure Report Card. https://www.infrastructurereportcard.org/wpcontent/uploads/2016/10/2017-Infrastructure-Report-Card.pdf

Berger, P. (2020a, May 27). Advocates press for bike lanes; City says cuts make it tough. The Wall Street Journal.

Berger, P. (2020b, October 20). Nearly 25\% of New York City transit workers cited Covid-19 infections, study says. The Wall Street Journal.

Cusumano, K. (2020, August 1). How to stay safer on mass transit. The New York Times.

De Sapio, J. (2013). Transient communities: Travel, knowledge, and the Victorian railway carriage, 18401890. Mobilities, 8(2), 201-219. http://dx.doi.org/10.1080/17450101.2012.659472

Desmond, M. (2016). Evicted. Broadway Books.

The destiny of density. (2020, June 13). The Economist, 435(9198), 14-16.

Durkin, E., \& Kapos, S. (2020, May 19). From goody-two-shoes to pariah: How coronavirus is changing public transportation. Politico.

EBP US, Inc. (2020, May 5). The impact of the COVID-19 pandemic on public transit funding needs in the U.S. American Public Transportation Association. https://www.apta.com/wpcontent/uploads/APTA-COVID-19-Funding-Impact-2020-05-05.pdf

Federal Transit Authority. (2020, September 28). The National Transit Database (NTD). https://www.transit.dot.gov/ntd

Goldbaum, C. (2020a, August 2). Is the subway risky? It may be safer than you think. The New York Times.

Goldbaum, C. (2020b, May 8). Stopped in its tracks: Scenes from a subway shutdown. The New York Times.

Iclodean, C., Cordos, N., \& Varga, B. O. (2020). Autonomous shuttle bus for public transportation: A review. Energies, 13(11), 2917. https://doi.org/10.3390/en13112917

Journey to recovery. (2020, April 16). Beijing Review, 63(16), 16-17.

Karner, A. \& Duckworth, R. (2019). "Pray for transit”: Seeking transportation justice in metropolitan Atlanta. Urban Studies, 56(9), 1882-1900. https://doi.org/10.1177/0042098018779756

Karner, A., \& Marcantonio, R. (2018). Achieving transportation equity: Meaningful public involvement to meet the needs of underserved communities. Public Works Management \& Policy, 23(2), 105-126. https://doi.org/10.1177/1087724X17738792

Klinenberg, E. (2018). Palaces for the people: How social infrastructure can help fight inequality, polarization, and the decline of civic life. Broadway Books. 
Lasswell, H. (1936). Politics. Who gets what, when, how. McGraw-Hill.

Lazo, L. (2020, July 11). America's 3000 bus companies make appeal for economic relief amid pandemic. The Washington Post.

Manjoo, F. (2020, July 12). I’ve seen a future without cars, and it's amazing. The New York Times.

Mass Transit Authority (n.d.). MTA action plan for a safe return. https://new.mta.info/coronavirus/reopening-plan

Morenne, B., \& Ngo, V. (2020, June 22). Train drain: How social distancing is transforming mass transit; in Paris, strict measures have dented by more than $70 \%$ on some mass-transit lines, hampering the resumption of normal business and social life. The Wall Street Journal.

National Academies of Sciences, Engineering, and Medicine (2009). Local and regional funding mechanisms for public transportation. https://doi.org/10.17226/14187.

Skoutelas, P. (2020, July 20). COVID-19 isn't killing mass transit. It's showing how much we need it. Chicago Tribune.

Smith, C. (2020, August 31). Rural California transit agency reinvents itself during COVID. Governing: The Future of States and Localities. https://www.governing.com/now/Rural-California-Transit-AgencyReinvents-Itself-During-COVID.html

Tan, S., Fowers, A., Keating, D., \& Tierney, L. (2020, May 15). Amid the pandemic, public transit is highlighting inequalities in cities. The Washington Post.

https://www.washingtonpost.com/nation/2020/05/15/amid-pandemic-public-transit-ishighlighting-inequalities-cities/?arc404=true

Taylor, B., \& Morris, E. (2015, March). Public transportation objectives and rider demographics: Are transit's priorities poor public policy? Transportation, 42(2), 347-367.

The National Academies of Sciences, Engineering, and Medicine. (2014). A guide for public transportation pandemic planning and response. https://www.nap.edu/catalog/22414/a-guide-for-publictransportation-pandemic-planning-and-response

Verma, P. (2020, August 15). We're desperate: Transit cuts felt deepest in low-income areas. The New York Times.

Vielkind, J., \& Berger, P. (2020, September 10). New York City subway and bus riders face $\$ 50$ fine for not wearing a mask. The Wall Street Journal.

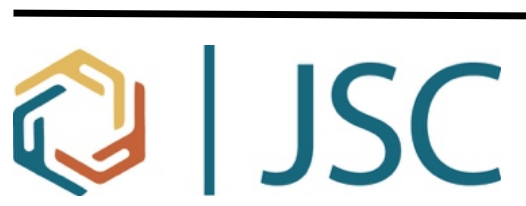

The Journal of Social Change, sponsored by Walden University, welcomes manuscripts focusing on interdisciplinary research in social change that improves the human condition and moves people, groups, organizations, cultures, and society toward a more positive future. 